\section{Reply to comment on "Prevalence of clinically important posterior fossa emissary veins on CT angiography"}

Sir,

We appreciate the comments of Konstantinos, et al. ${ }^{[1]}$ on our article ${ }^{[2]}$ that gives additional information about anatomy and importance of the anterior and lateral condylar veins. This comment also emphasizes the value of knowing venous anatomy of the craniocervical region when treating the dural arteriovenous fistulas of the anterior condylar canal or attempting selective retrograde venous catheterization. Although there are some studies that give the prevalence of the various posterior fossa emissary veins on $\mathrm{CT},{ }^{[3]}$ most of the studies are cadaveric studies. ${ }^{[4-6]}$ This is the first study that report the prevalence of the major posterior fossa emissary veins on CT angiography in general population. As we mentioned in the limitation paragraph of our study it was a retrospective study and we evaluated routine cervical ct angiography examinations that were not done primarily to display craniocervical complex venous anatomy. We tried to evaluate the prevalence of the emissary veins that can be easily seen on routine cervical ct angiography exams and emphasize the importance of reporting these vessels, especially in patients who will undergo mastoid and posterior fossa surgery. Additionally, due to limitation of the CT angiography technique, depiction of very small emissary veins could have been missed and might be beyond the capability of the CT examinations. Therefore, we only evaluated the major posterior fossa emissary veins that can be easily seen on CT angiography. Anterior and lateral condylar veins are also clinically important but they are very difficult to evaluate on routine CT angiography images. Conventional angiography that can also give opportunity to treat dural arteriovenous fistulas may be more helpful and still gold standard assessment tool. Due to the overlapping bone structures, it is difficult to demonstrate the detailed vascular pattern and to make a diagnosis of dural arteriovenous fistulas with conventional CT angiography, especially in small vessels. Recently due to new algorithms and postprocessing techniques, CT angiography may also be used to evaluate the dural arteriovenous fistulas. ${ }^{[7]}$ But the technique should focus on cranial cervical arteriovenous anatomy.
Yeliz Pekcevik

Izmir Tepecik Training and Research Hospital, Department of Radiology

Address for correspondence: Dr. Yeliz Pekcevik,

Izmir Tepecik Training and Research Hospital, Department of Radiology Gaziler Cd No: 468, Yenişehir TR-35110 Izmir/Turkey. E-mail: yelizpekcevik@yahoo.com

\section{References}

1. Konstantinos N, Maria P. The anatomical variability of the emissary condylar veins, its identification and clinical significance. J Neurosci Rural Pract 2015;6:125-6.

2. Pekcevik Y, Sahin H, Pekcevik R. Prevalence of clinically important posterior fossa emissary veins on CT angiography. J Neurosci Rural Pract 2014;5:135-8

3. Koesling S, Kunkel P, Schul T. Vascular anomalies, sutures and small canals of the temporal bone on axial CT. Eur J Radiol 2005;54:335-43.

4. San Millán Ruíz D, Gailloud P, Yilmaz H, Perren F, Rathgeb JP, Rüfenacht DA, et al. The petrosquamosal sinus in humans. J Anat 2006;209:711-20.

5. Marsot-Dupuch K, Gayet-Delacroix M, Elmaleh-Bergès M, Bonneville F, Lasjaunias P. The petrosquamosal sinus: CT and MR findings of a rare emissary vein. AJNR Am J Neuroradiol 2001;22:1186-93.

6. Chauhan NS, Sharma YP, Bhagra T, Sud B. Persistence of multiple emissary veins of posterior fossa with unusual origin of left petrosquamosal sinus from mastoid emissary. Surg Radiol Anat 2011;33:827-31.

7. Lee CW, Huang A, Wang YH, Yang CY, Chen YF, Liu HM. Intracranial dural arteriovenous fistulas: Diagnosis and evaluation with 64-detector row CT angiography. Radiology 2010;256:219-28.

\begin{tabular}{|l|l|}
\hline \multicolumn{2}{|c|}{ Access this article online } \\
\hline Quick Response Code: & Website: \\
\hline & www.ruralneuropractice.com \\
\hline & \\
\hline
\end{tabular}

